\title{
The impact of some wine-making practices on the quality of Vranec red wines from Macedonia produced by the newly-selected local strain "F-78"
}

\author{
Fidanka Ilieva $^{\mathrm{a}, \mathrm{b}}$, Sanja Kostadinović Veličkovska ${ }^{\mathrm{b}, *}$, Violeta Dimovska ${ }^{\mathrm{b}}$, Hristo Spasov ${ }^{\mathrm{a}}$ \\ a Department of Wine and Beer Technology, University of Food Technologies, Marica 26, Plovdiv, Bulgaria \\ ${ }^{\mathrm{b}}$ Faculty of Agriculture, University “Goce Delčev”, Krste Misirkov bb, 2000 Štip, Macedonia
}

\section{A R T I C L E I N F O}

\section{Article history:}

Received 7 April 2015

Received in revised form 18 August 2015

Accepted 20 August 2015

Available online 25 August 2015

\section{Keywords:}

Vranec wines

Wine-making practices

Monomeric anthocyanins

Total phenolic compounds

Yeast strain F-78

\begin{abstract}
A B S T R A C T
The impact of enological practices (temperature, flipping and the inoculation amount of newly selected yeast F-78 from third-stage selection) on the level of monomeric anthocyanins, total phenolic compounds and the overall taste of fifteen red wines from Macedonian Vranec grape variety were studied. The most important factor which affects the level of monomeric anthocyanins was temperature. The inoculation amount had a positive influence on the phenolic extraction. More inoculation amount leads to faster ethanol formation and acceleration of the anthocyanins extraction. The flipping of the must during fermentation was controversial. The best wine-making procedure for production of the typical for the region high-extractive aged wines included a fermentation temperature of $20-24^{\circ} \mathrm{C}$, intensive flipping (5-6 times/24 h), and inoculation quantity $3-4 \%$ and a fermentation on $20^{\circ} \mathrm{C}$, medium flipping (3-4 times/24 h) and inoculation quantity $3-4 \%$ for production of commercial, young and easy to drink "Beaujoulais" wines.
\end{abstract}

(c) 2015 Elsevier Ltd. All rights reserved.

\section{Introduction}

In present days, mainly pure selected cultures of wine yeasts are used in winemaking, which led to a significant improvement of the wine technology, because of the multiple benefits: ability to a quick and effective fermentation of grape juice or must with high sugar concentration; tolerance to high levels of ethanol and $\mathrm{SO}_{2}$; resistibility to high temperatures during fermentation (Bosso, Guaita, Panero, Borsa, \& Follis, 2009). The increasing usage of trade produced selected yeasts for winemaking really lead to a lost of the natural and regional populations of yeasts. The relationship between growing region, cultivar, climate and microbial biogeography of 273 grape must samples from the region of California in two separated vintages (2010 and 2012) has been the focus of study of Bokulich et al. The group of Bokulich confirmed nonrandom regional distribution of grape microbiota across growing regions. The growing regions included in this study were distinguished by several key groups of grapevine fungi and bacteria. It demonstrated that microbiological community patterns across the regions and vintages depended from grape variety and

\footnotetext{
* Corresponding author.

E-mail address: sanja.kostadinovik@ugd.edu.mk (S.K. Veličkovska).
}

local environmental conditions (Bokulich, Thorngate, Richardson, \& Mills, 2014).

The most used trade produced yeast belongs to Saccharomyces species but, other species of yeasts such Hanseniaspora, Kluyveromyces, Metchnikowia, Candida, Zygosaccharomyces, Brettanomyces can be active at different stages during fermentation and destructive for wine favor. Therefore, the group of Bokulich, developed terminal restriction fragment length polymorphism (TRFLP) approach for profiling the yeast community of wine (Bokulich, Hwang, Liu, Boundy-Mills, \& Mills, 2012).

Last few years, an increasing interest among scientist and winemakers in the local yeast cultures was observed. After selection, yeast cultures with good characteristics could be applied successfully in winemaking (Sacchi, Bisson, \& Adams, 2005).

The quality markers of red wines from Vranec variety were published by few researchers in the last few years. The effect of enological practices on the stilbene levels in Vranec wines was published by Kostadinović et al. (2012). According to their findings, the most important factor for the level of trans-resveratrol and its piceid in Vranec wines was maceration time. Although both yeasts, i.e. "Levuline CHP" and "Vinalco" belong to the same group of Saccharomyces cerevisiae, higher concentrations of trans-resveratrol and piceid have been obtained with French yeast "Levuline CHP" 
in comparison to Macedonian yeast "Vinalco". Total phenolic acid and anthocyanins were higher in Vranec wines produced with locally isolated yeasts in comparison to wines fermented with commercial yeasts (Ivanova-Petropulos, Ricci et al., 2015).

Analyses of non-colored phenolics in red wines produced from grapes from Touriga Nacional wine growing area of the Dão region (Portugal) showed that in all samples (inoculated and non inoculated) the level of phenolic acids dominated over flavonoids (Silva, Andrade, Valentão, Seabra, \& Velázquez, 2005). The group of Medina explored how growth of non-Saccharomyces yeasts can affects nutrient availability for $S$. cerevisiae during wine fermentation (Medina, Boido, Dellacassa, \& Carrau, 2012). They revealed that yeast can produced numerous secondary metabolites during fermentation that impact final wine quality. Selection of two non-Saccharomyces yeasts can positively affect the flavor of wines. They selected strains of Hanseniaspora vineae and Metschnikowia pulcherrima which had different yeast assimilable nitrogen consumption profiles and had different effects on S. cerevisiae fermentation and growth kinetics. The results indicated sluggish fermentations as more pronounced when $S$. cerevisiae was inoculated $24 \mathrm{~h}$ after the initial stage of fermentation with a nonSaccharomyces yeasts compared to co-inoculation. The effect of Saccharomyces strains on the quality of red wines aged on lees was object of study of Loira et al. (2013). Regarding the strains tested, "G-37" showed the highest production of polysaccharides as well as vanillin, syringaldehyde and furfuryl alcohol. The wine aged with CTPL14 strain had fewer monomeric and oligomeric proanthocyanidins and showed the lowest astringency and bitterness sensations (Loira et al., 2013).

The group of Favre stated that Tannat red wines produced by traditional maceration increased unequally wine phenolics, addition of grape seed tannins increased flavan-3-ols with low molecular weight, prefermentative cold maceration increased anthocyanins and maceration enzyme increased proanthocyanidins in the level up to $2250 \mathrm{mg} / \mathrm{L}$ (Favre et al., 2014).

Vranec wines had the highest concentration of anthocyanins (508 mg/L) in comparison to Cabernet Sauvignon and Merlot wines (Ivanova-Petropulos, Hermosín-Gutiérrez et al., 2015). The phenolic profile of wines produced from the Vranec variety of grapes showed $1515 \mathrm{mg} / \mathrm{L}$ total phenolics, $1103 \mathrm{mg} / \mathrm{L}$ total flavonoids, $237 \mathrm{mg} / \mathrm{L}$ total anthocyanins and $845 \mathrm{mg} / \mathrm{L}$ total catechins (Ivanova, Stefova, \& Chinnici, 2010).

Regarding the importance and influence of the yeasts in physico-chemical and organoleptic characteristics of the wines, this work for the first time considered the isolation, selection and the impact of the new yeast "F-78" in a selected area for a production of regional wines with appellation from the Vranec variety.

The aim of this study was to explain the impact of enological practices (temperature, inoculation amount and flipping frequency) and newly selected yeast "F-78" on the anthocyanins monomers and total phenolic content in 15 Vranec wines from the region of Macedonia. Furthermore, the impact of winemaking practices on the overall quality and taste of Vranec wines in terms of color, flavor, acidity, aftertaste, texture and balance was studied in order to find out the best wine-making procedure as combination of few parameters for producing of high quality young and aged Vranec wines.

\section{Materials and methods}

\subsection{Grapes for spontaneous fermentation}

For the fermentation purposes in semi-industrial conditions, a grape variety Vranec, from Tikveš region was used.

The grapes from the Vranec variety were picked up in optimal maturity (150 kg of Vranec grapes, sugar content $22-24.8 \%$, titratable acidity 3.95-7.67 g/L and $\mathrm{pH} 3.35-3.62$ ) and processed under microvinification conditions following the classic protocol for spontaneous fermented regional red wines with sulfites addition (Table 1).

\subsection{Sterilized grape juice during selection}

For the selection of the strains, a sterilized grape juice from Vranec variety with sugar content $215 \mathrm{~g} / \mathrm{L}$, titratable acidity $4.14 \mathrm{~g} / \mathrm{L}$ and $\mathrm{pH} 3.52$ was used. The grapes were destemmed, crushed and proportionally shared out, which assured the uniformity of the raw material. Furthermore, the grape mash was divided into 10 lots collected in $25 \mathrm{~L}$ plastic fermentation tanks. Aqueous solutions of potassium metabisulphite were added to the mashes with $20 \mathrm{mg} / \mathrm{L}$ of total $\mathrm{SO}_{2}$ and the Vranec wine was produced by natural malolactic fermentation.

\subsection{Isolation of wine yeast strains from spontaneous fermented wines from Tikveš region}

\subsubsection{Spontaneous fermentation of grape must from Vranec grapes}

A spontaneous fermentation of ten different lots of Vranec grapes from different micro regions was held from the harvest 2010. Some data about the lots are given in Table 1 . The operations such destemming, crushing and sulfites addition (dosage $20 \mathrm{mg}$ / $\mathrm{kg}$ ) were performed. The spontaneous fermentation ran at $25-28^{\circ} \mathrm{C}$ in PET vessels.

After the end of the alcoholic fermentation we performed some analysis on the trial wines such the alcohol concentration, residual sugars, titratable and volatile acidity, $\mathrm{pH}$, monomeric anthocyanins and color intensity. Organoleptic characteristics of the trial wines were evaluated. Based on the summarized data, estimation was made for spontaneous fermented wines which are the most appropriate for isolation of yeast strains.

\subsubsection{Isolation of pure cultures yeast strains}

From the trials, pure yeast cultures were isolated following the Koch method (Bambalov, Spasov, \& Bambalov, 2000). The isolation was performed from single colonies, cultivated on firm nutrient medium, in test tubes with sterilized grape juice, in thermostat at $25^{\circ} \mathrm{C}$. Subsequently, the isolated strains were put on a triplestage selection.

Table 1

Grapes for the spontaneous fermentation, selection of yeasts and production of Vranec wines by application of newly isolated yeast F-78.

\begin{tabular}{|c|c|c|c|c|}
\hline Grape variety "Vranec" & Delivery period & Sugar content (\%) & Acidity $(\mathrm{g} / \mathrm{L})$ & $\mathrm{pH}$ \\
\hline For spontaneous fermentation & $15-29.09 .2010$ & $22-24.8$ & $3.95-7.67$ & $3.35-3.62$ \\
\hline For selection of yeasts & 13.09.2011 & 21.2 & 6.33 & 3.41 \\
\hline For production of wines by application of yeast "F-78" & 01.09 .2012 & 23.1 & 7.13 & 3.32 \\
\hline
\end{tabular}




\subsubsection{Triple-stage selection of the newly selected strains}

During the first stage selection, the fermentation activity of 80 newly selected strains in sterilized grape juice was studied. $10 \mathrm{~cm}^{3}$ of grape juice which consisted $22.25 \%$ dry matter was inoculated in sterilized lab tubes by inoculating loop with previously activated 72 -h yeast culture. The grape juice was thermostated at $25{ }^{\circ} \mathrm{C}$ and the dynamic of the alcoholic fermentation was checked with refractometer. During the first stage selection 40 strains were selected.

During the second stage selection, sterilized grape juice was poured in glass bottles of $330 \mathrm{~cm}^{3}$ with sugar concentration of $222 \mathrm{~g} / \mathrm{L}$, dry matter $22.45 \%$, titratable acidity of $4.14 \mathrm{~g} / \mathrm{L}$ and $\mathrm{pH}$ 3.52. The first-stage selected 40 strains were inoculated in the prepared bottles with amount of $2 \mathrm{~cm}^{3}$ liquid inoculation culture. The bottles were closed with fermentation caps and the course of the fermentation was monitored by the weight method. After the end of the alcoholic fermentation, the analysis of sugar content, titratable acidity, volatile acidity and percentage of alcohol were performed. The coefficients of transformation of sugars into ethanol of the yeasts were calculated. Based on the summarized results, 10 yeasts strains were selected on the second stage selection.

During the third stage of selection, we made trial wines with 10 selected strains on the second stage. The grapes were provided from the estate vineyards from harvest 2011. The grapes were equally allocated to the different lots. The berries were exuded from the cluster by hand and $15 \mathrm{~kg}$ of Vranec grapes were weighed and crushed by hand crusher. After the crush, the must was put in plastic bottles of $20 \mathrm{~L}$ and added $20 \mathrm{mg} / \mathrm{kg} \mathrm{SO}_{2}$. After two hours, the must was inoculated with the previously cultivated liquid culture of studied strains from sterilized grape juice. We performed 10 trial lots with selected yeast strains, added a control, which was inoculated with commercial strain wine yeast S. cerevisiae, strain D 576 "SiHa active yeast 7" (Begerow E. GmbH \& Co, Langenlonsheim, Germany).

After the peak of the fermentation, the trials were left for 20 days more, allowing the fermentation to end smoothly. After that, the pomace was removed and the wine obtained was put in other PET vessels. The trials were inoculated with the pure culture malolactic bacteria "Viniflora CiNe" (Chr Hansen, Hørsholm, Denmark) in order to maintain fermentation. The course of the malolactic fermentation was monitored by paper chromatography. After the end of the malolactic fermentation (the level of malic acid was $0.09 \mathrm{~g} / \mathrm{L}$ ), the sulfites addition was performed to $20 \mathrm{mg} / \mathrm{L}$ free sulfur dioxide. The wines were poured in glass bottles and stored under cellar conditions. In the final wine, we measured the alcohol content, residual sugars, titratable acidity, volatile acidity, total phenolic compounds, total monomeric anthocyanins and color characteristics.

Based on these results, the third-stage selection was made and the final choice of a strain "F-78", which could be recommended for industrial production of regional wine from Tikveš region was done.

\subsubsection{Application of yeast strains F-78 from third-stage selection in the} wine-making of red Vranec wines

Vranec grapes from harvest 2012 were equally allocated to the lots, in order to make similar fermentation conditions. $7 \mathrm{~kg}$ destemmed grape grains were crushed with manual crusher. After crushing, $20 \mathrm{mg} / \mathrm{kg}$ free $\mathrm{SO}_{2}$ was added in the must (7 kg) and it was transferred into $10 \mathrm{~L}$ PET bottles. After two hours, the must was inoculated with culture of the third-stage selected strain F-78. The total culture addition was performed during 96-h (Table 1).

The trial was held under the conditions of planned tri-factorial experiment Box-Behnken. The effects of three factors, in particular: variation of the alcoholic fermentation temperature, quantity of the inoculation culture and flipping of the fermentative must were studied. The planned trials were performed in order to study the influence of the factors, mentioned above on the total monomeric anthocyanins and total phenolic compounds dynamics of the trial wines as well as organoleptic profile of produced wines. Every trial of tri-factorial experiment was repeated resulting in production of 30 Vranec wines. As shown in Tables 2 and 4, the content of monomeric anthocyanins and total phenolic compounds are expressed in $\mathrm{mg} / \mathrm{L} \pm \mathrm{SD}$ of two replicates.

The three factors had variation levels as follows:

Temperature

- low level - $20^{\circ} \mathrm{C}$;

- medium level $-24^{\circ} \mathrm{C}$;

- upper level $-28^{\circ} \mathrm{C}$.

Inoculation amount

- low level - $2 \%$;

- medium level - $3 \%$;

- upper level - $4 \%$.

Flipping

- low level - 2 times per day on every $12 \mathrm{~h}$;

- medium level - 4 times per day on every 6 h;

- upper level - 6 times per day on every $4 \mathrm{~h}$.

The plan of the experiment Box-Behnken with the variables is shown on Tables 2 and 4 . Every variant is made in two repetitions.

Table 2

Dynamics of the monomer anthocyanins in the Vranec wines.

\begin{tabular}{|c|c|c|c|c|c|c|c|}
\hline Vranec wines & $T\left({ }^{\circ} \mathrm{C}\right)$ & Inoculation amount (\%) & Flipping (num/24 h) & 2nd day & 5th day & 9th day & 30th day \\
\hline Wine 1 & 24 & 3 & 4 & $327.0 \pm 3.2^{g}$ & $669.8 \pm 2.0^{\mathrm{d}}$ & $608.2 \pm 4.5^{\mathrm{g}}$ & $379.2 \pm 4.2^{\mathrm{b}, \mathrm{c}}$ \\
\hline Wine 2 & 24 & 3 & 4 & $368.7 \pm 2.4^{\mathrm{d}}$ & $817.5 \pm 2.5^{a}$ & $623.7 \pm 5.0^{f}$ & $362.5 \pm 3.5^{\mathrm{d}, \mathrm{e}}$ \\
\hline Wine 3 & 24 & 3 & 4 & $327.1 \pm 4.2^{\mathrm{g}}$ & $668.5 \pm 8.8^{\mathrm{d}, \mathrm{e}}$ & $562.7 \pm 11.4^{\mathrm{i}}$ & $389.4 \pm 11.4^{\mathrm{b}}$ \\
\hline Wine 4 & 20 & 2 & 4 & $249.2 \pm 5.0^{\mathrm{j}}$ & $488.7 \pm 4.9^{\mathrm{h}}$ & $472.4 \pm 6.3^{1}$ & $372.1 \pm 3.9^{\mathrm{c,d}}$ \\
\hline Wine 5 & 28 & 4 & 4 & $346.3 \pm 4.4^{\mathrm{e}, \mathrm{f}}$ & $738.1 \pm 9.9^{c}$ & $688.4 \pm 2.5^{\mathrm{d}}$ & $408.6 \pm 4.5^{\mathrm{a}}$ \\
\hline Wine 6 & 20 & 3 & 2 & $269.4 \pm 2.3^{\mathrm{i}}$ & $623.2 \pm 9.3^{f}$ & $625.4 \pm 5.5^{\mathrm{e}, \mathrm{f}}$ & $342.2 \pm 4.2^{\mathrm{f}}$ \\
\hline Wine 7 & 28 & 3 & 6 & $325.4 \pm 5.6^{\mathrm{g}, \mathrm{h}}$ & $658.7 \pm 23.7^{\mathrm{d}, \mathrm{e}}$ & $572.5 \pm 3.0^{\mathrm{i}}$ & $361.4 \pm 2.9^{\mathrm{d}, \mathrm{e}}$ \\
\hline Wine 8 & 28 & 3 & 2 & $399.4 \pm 4.1^{\mathrm{b}}$ & $820.2 \pm 4.5^{\mathrm{a}}$ & $775.6 \pm 4.7^{\mathrm{a}}$ & $408.1 \pm 6.1^{a}$ \\
\hline Wine 9 & 24 & 4 & 6 & $314.0 \pm 12.4^{\mathrm{h}}$ & $725.5 \pm 8.1^{\mathrm{c}}$ & $583.3 \pm 2.0^{\mathrm{h}}$ & $305.1 \pm 8.3^{g}$ \\
\hline Wine 10 & 20 & 4 & 4 & $354.9 \pm 6.9^{\mathrm{e}}$ & $646.5 \pm 17.5^{\mathrm{e}}$ & $587.2 \pm 4.4^{\mathrm{h}}$ & $316.8 \pm 7.7^{g}$ \\
\hline Wine 11 & 24 & 2 & 2 & $342.4 \pm 5.5^{\mathrm{f}}$ & $572.1 \pm 4.4^{\mathrm{g}}$ & $522.5 \pm 1.1^{\mathrm{k}}$ & $248.3 \pm 9.9^{h}$ \\
\hline Wine 12 & 28 & 2 & 4 & $382.5 \pm 4.7^{c}$ & $609.8 \pm 12.2^{\mathrm{f}}$ & $540.6 \pm 1.1^{\mathrm{j}}$ & $341.6 \pm 2.2^{f}$ \\
\hline Wine 13 & 20 & 3 & 6 & $351.7 \pm 3.3^{\mathrm{e}, \mathrm{f}}$ & $664.5 \pm 8.7^{\mathrm{d}, \mathrm{e}}$ & $635.9 \pm 5.9^{\mathrm{e}}$ & $358.3 \pm 10.2^{\mathrm{d}, \mathrm{e}}$ \\
\hline Wine 14 & 24 & 4 & 2 & $389.1 \pm 6.5^{\mathrm{b}, \mathrm{c}}$ & $718.5 \pm 1.8^{\mathrm{c}}$ & $702.2 \pm 4.8^{\mathrm{c}}$ & $387.8 \pm 3.2^{\mathrm{b}}$ \\
\hline Wine 15 & 24 & 2 & 6 & $466.5 \pm 6.7^{\mathrm{a}}$ & $769.0 \pm 14.8^{\mathrm{b}}$ & $720.8 \pm 1.8^{b}$ & $353.1 \pm 5.4^{\mathrm{e}, \mathrm{f}}$ \\
\hline
\end{tabular}

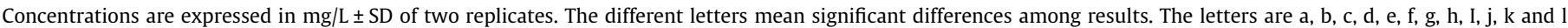
according to the decrease of the result values. 
Table 3

Significant probability ( $p$-values and F-ratio) of the independent variable effects (temperature, inoculation amount, and flipping) on the level of monomer anthocyanins.

\begin{tabular}{|c|c|c|c|c|c|}
\hline Factor & & 2nd day & 5th day & 9th day & 30th day \\
\hline \multirow{2}{*}{ Temperature $\left({ }^{\circ} \mathrm{C}\right)$} & $p$-Value & $0.038^{a}$ & $0.005^{\mathrm{a}}$ & 0.202 & 0.147 \\
\hline & $F$-ratio & 3.79 & 6.60 & 1.72 & 2.08 \\
\hline \multirow[t]{2}{*}{ Inoculation amount (\%) } & $p$-Value & 0.596 & $\mathbf{0 . 0 0 8}^{\mathrm{a}}$ & 0.080 & $0.044^{\mathrm{a}}$ \\
\hline & $F$-ratio & 0.53 & 5.91 & 2.83 & 3.59 \\
\hline \multirow[t]{3}{*}{ Flipping (times/24 h) } & $p$-Value & 0.45 & 0.522 & 0.079 & 0.253 \\
\hline & $F$-ratio & 0.83 & 0.67 & 2.84 & 1.46 \\
\hline & $R^{2}$ & 0.315 & 0.535 & 0.397 & 0.385 \\
\hline
\end{tabular}

a Significant at $p<0.05$.

Direct method of cooling was applied by cooling the double walls of fermentation tanks with water and the fermentation course was observed with Abbe's refractometer.

After the peak of the fermentation, we separated the wine from the lees, add sulfites to $20 \mathrm{mg} / \mathrm{L}$ free $\mathrm{SO}_{2}$, separated the additionally formed lees and preserved the wine in glass bottles.

Samples of the variants included in the experiment were taken on four stages of the alcoholic fermentation (AF): 2nd day (beginning of the AF), 5th day (middle of the AF), 9th day (end of the AF) and 30th day (after MLF). All of the samples were analyzed for monomeric anthocyanins concentration and total phenolic compounds.

\subsection{Determination of color, total anthocyanins and total phenolic compounds}

Determination of color characteristics was performed spectrophotometrically by measuring the absorbance of the wines at $420 \mathrm{~nm}$ (yellow color), $520 \mathrm{~nm}$ (red color) and $620 \mathrm{~nm}$ (blue color) with UV spectrophotometer Shimadzu 1800, Shimadzu Corporation, Kyoto, Japan. Determination of monomeric anthocyanins and total phenolic compounds was performed by colorimetric method (Singleton \& Rossi, 1965).

\subsection{Sensory analyses of the organoleptic profile of Vranec wines}

All the tasting sessions took place in a specific room equipped with individual booths and air-conditioned at $20^{\circ} \mathrm{C}$. Normalized glasses were used. All wines were tasted nine times by 10 trained sensory panelists in ages between 40 and 55 ( 3 females/7 males). The panelists were selected on the bases of their past experience in wine-making and tasting the flavor of red wines. For purpose of this experiment, they were trained over the period of 45 days to assess wine aroma using AROXA ${ }^{\mathrm{TM}}$ Uno Wine Flavour Standard kit (supplied by AROXA, Leatherhead Surrey, UK). The AROXA ${ }^{\mathrm{TM}}$ Uno Wine Flavour Standard kit was composed of ten different wine flavors (dimethyl sulfide, 4-ethyl phenol, ethyl phenylacetate, hydrogen sulfide, $\beta$-ionone, isovaleric acid, 2-isobutyl-3methoxypyrazine, sotolon, 2,4,6-trichloroanisol and vanillin). The training was carried out twice per week for $30 \mathrm{~min}$. In this study, panelists were asked to describe wine aroma with their own vocabulary.

\subsection{Statistical analyses}

A Box-Behnken factorial design with three factors and three levels, including two replicates at the center point, was used in order to generate 15 treatment combinations, with variation of the alcoholic fermentation temperature, quantity of the inoculation culture and the flipping of the fermentative must as variables. The data for phenolic compounds were subjected to the General
Linear Model (GLM) to determine the significant main effects $(p<0.05)$ of independent variables, namely, temperature $(20,24$ and $\left.28^{\circ} \mathrm{C}\right)$, inoculation amount (2, 3 and $4 \%$ ) and flipping (2, 4 and 6 times/24 h) on the level of monomer anthocyanins and total phenolic content in Macedonian red wines from the varieties Vranec (Tables 3 and 5 ). The corresponding variables are statistically significant $(p<0.05)$ if the absolute $F$ ratio becomes larger and the $p$-value becomes smaller. The data analysis was performed by using the Minitab v. 13.2 (Minitab Inc., State College, PA, USA).

Furthermore, a one-way ANOVA was used to examine the level of every particular enological factor on the level of total monomeric anthocyanins and total phenolic content. The level of significance of differences between the anthocyanins content and total phenolic content was determined at $5 \%$ by a one-way ANOVA using Tukey's test. The ANOVA results were classified using letters (different letters mean significant differences among results). The letters are a, b, c, d, e, f, g, h, i, j, k and l according to the decrease of the result values. This treatment was carried out using SPSS v.16.0 software, IBM Corporation, USA.

\section{Results and discussion}

In this work, the third-stage selected strain F-78 was used. The math modeling of the influence of the factors temperature, inoculation amount and flipping on the anthocyanins and total phenols concentration was performed. The analysis took place at the 2 nd, 5th, 9th and 30th day since the alcoholic fermentation beginning. The math modeling was done by Box-Benker planned experiment to establish the influence of the factors mentioned from higher level.

\subsection{The impact of enological practices on total monomeric anthocyanins in Vranec red wines with the third-stage selected yeast} strains

The data for the monomer anthocyanins in the different stages namely 2nd, 5nd, 9nd and 30nd day of alcoholic fermentation was presented in Table 2.

The data from the math model of anthocyanins formation on 2th day shows a different impact of the three factors. The highest level of monomer anthocyanins $(466.5 \pm 6.7 \mathrm{mg} / \mathrm{L})$ on the 2th day of alcoholic fermentation was detected in Vranec wine 15 produced at $24{ }^{\circ} \mathrm{C}$, inoculation amount of $2 \%$ and the highest rate of flipping. The effect of temperature on the level of monomeric anthocyanins was statistically significant ( $p$-value is 0.038 ). Vranec wines 2 and 8 had very similar level of monomer anthocyanins $817.5 \pm 2.5$ and $820.2 \pm 4.5 \mathrm{mg} / \mathrm{L}$ respectively on the 5th day of alcoholic fermentation. Vranec wine 2 was produced at $24{ }^{\circ} \mathrm{C}$ and medium rate of flipping and Vranec wine 8 at $28^{\circ} \mathrm{C}$ and the lowest rate of flipping. Both wines were produced by inoculation amount of $3 \%$. Statistical analyses confirmed that the effects of temperature 
and inoculation amount were significant ( $p$-values 0.005 and 0.008 , respectively). Although the highest concentration of monomeric anthocyanins was detected in the same wine (Vranec 8) at 9th day of alcoholic fermentation, there no significant effect of all three factors. Almost identical concentration of monomeric anthocyanins was detected in Vranec wines 5 and 8 produced at $28{ }^{\circ} \mathrm{C}$ and inoculation amount of $4 \%$ and 3\%, respectively. Only the inoculation amount had significant effect on the level of monomeric anthocyanins at 30th day.

Vranec grape variety is famous by high level of monomeric anthocyanins. In the work of Kostadinović et al., significant amounts of monomeric anthocyanins were isolated from grape pomace of this variety of grapes after 20 days of maceration time. The highest abundance of malvidin-3-glucoside as well as other monomeric anthocyanins as dephinidin-3-glucoside, cyaniding-3glucoside, petunidin-3-glucoside, peonidin-3-glucoside and malvidin-3-p-coumaroyl-glucoside was isolated from the grape pomace of Vranec variety in comparison to Merlot and Pinot Noir grape variety (Kostadinović-Veličkovska, Mirhosseini, \& Bogeva, 2013). However, temperature increased the extraction of anthocyanins in the level of ethanol formed at the 2th day of fermentation. The significant effect of temperature at the 2th day of maceration ( $p$-value was 0.038 ) can be explained due to the fact that 2th day of maceration time is very early stage of the fermentation following by the lack of the extracting action of the ethanol and the still running maceration of the vegetal cell walls. Hence, the temperature can affect the lowest level of monomeric anthocyanins and increased the extraction rate.

During the fermentation's peak (5th day) the impact of the different factors changed. For example, the high amount of inoculation yeasts, which led to intensive alcohol formation, has a positive impact on the anthocyanins formation ( $p$-value was 0.008 ). The higher ethanol concentration helps the extraction process. It is well known that implication of the yeasts in the typical color of red wines is twofold. On one hand, wine yeasts influence the extraction of grape anthocyanins during maceration and fermentation, depending on their alcohol production capacity. According to the findings of Vasserot et al., the yeast and yeast hulls can bind a non negligible amount of monomeric anthocyanins which depends on the chemical structure of anthocyanins, temperature, $\mathrm{pH}$ and $\mathrm{SO}_{2}$ concentration (Vasserot, Caillet, \& Maujean, 1997). They also influence the formation of more stable anthocyanin forms during maturation and aging. On the other hand, yeasts can promote anthocyanin degradation and participate in certain interactions with colorless pigments that result in color loss. Under these conditions, the temperature impact is weaker, but generally positive for anthocyanins extraction ( $p$-value is 0.005). The tendency is in agreement with the findings of Reynolds et al. Their results showed tendency of increasing the level of monomeric anthocyanins during the fermentation peak (Reynolds, Cliff, Girard, \& Kopp, 2001). Furthermore, Puértolas et al. stated that maceration time and temperature did not influence significant on the anthocyanin profiles of Cabernet Sauvignon rosé wine (Puértolas, Saldaña, Álvarez, \& Raso, 2011). However, reduction of the temperature decreased oxidation of phenols which increased the overall taste of Cabernet Sauvignon rosé wines. Casassa et al. described the effect of cold soaking on the chromatic and phenolic composition on the quality of wines from six grape varieties Syrah, Cabernet Sauvignon, Malbec, Pinot Noir, Merlot and Barbera D'Asti. Their results indicated that cold soaking only affect the chromatic profile of the wines but, did not affect the total level of anthocyanins and tannins in final wines (Casassa, Bolcato, \& Sari, 2015).

The combinations of flipping with temperature and inoculation amount have negative impact. This could be explained by the fact that the intensive flipping can catalyze condensation of the anthocyanins with other colorless phenols in grapes, particularly monomeric and polymeric flavanols (catechins and procyanidins), flavonols and phenolic acids in polymeric pigments (Bakker, Preston, \& Timberlake, 1986). The great quantity of yeast cells had similar effect, because the yeasts can absorb anthocyanins on their surface (Kostadinović et al., 2012).

The end of the alcoholic fermentation leads to significant change in the different factors impact. On the 9th day, the three factors have negligible impacts on the anthocyanins concentration. We could assume that the extraction of anthocyanins is already done and the factors do not have a significant impact on the mass-exchange process (Bakker et al., 1998).

At the end of the interval studied (30th day), the condensation begins and relation of the monomeric anthocyanins with others wine compounds. This leads to decreased concentration of monomeric anthocyanins and increased concentration of polymeric pigments (Reynolds et al., 2001). In this case the model showed rather negative factors impact on the level of examined class of compounds. Furthermore, anthocyanins are phenolic compounds which are the most affected by the yeast strain. In the work of Monagas et al., diglycosidic anthocyanins were the most affected by the yeast strains in both grape varieties Tempranillo or Cabernet Sauvignon (Monagas, Gómez-Cordovés, \& Bartolomé, 2007). Except hydroxycinnamic acids and derivatives, all other phenolic compounds were less influenced by the yeast strain. The results from statistical analyses were in perfect agreement with this statement since the only significant factor was inoculation amount ( $p$-value 0.044).

Regarding the total monomeric anthocyanins content, we can summarized that temperature had rather positive impact on the anthocyanins formation. Our statement was in good agreement with results obtained in the work of Pérez-Lamela et al., regarding different enological treatments which were applied to the Spanish Mencía variety by addition of yeasts plus an enzyme. According to their results, cold maceration had negative impact of the content of anthocyanins. More precisely, cold maceration reduced anthocyanin content and enhanced a higher ionization index (PérezLamela, García-Falcón, Simal-Gándara, \& Orriols-Fernández, 2007).

Generally speaking, the inoculation amount had a positive influence on the anthocyanins formation with exception of the end of alcoholic fermentation when the concentrations of the monomeric anthocyanins were the highest (9th day). More inoculation amount leads to faster ethanol formation and acceleration the extraction of monomeric anthocyanins. The flipping of the must during fermentation was controversial. At one hand, the more flipping lead to better contact surface and intensive extraction, but on the other hand it favors the extraction of polymeric pigments.

\subsection{The impact of enological practices on total phenolic compounds in} Vranec red wines with the third-stage selected yeast strains

The same approach was followed in case of the total phenolics in the same Vranec wines (Table 4).

The extraction of total phenolic compounds in the wines run according the normal tendency in winemaking and basically increases during the fermentation. Generally, this class of compounds is more stable against quantity changes than the monomeric anthocyanins, which, after the peak on the 9th day, decrease twice until the 30th day. As we mentioned above, the behavior of monomeric anthocyanins can be explained by the fact that after the peak of alcoholic fermentation, they react with other phenolic compounds and formed stable polymeric pigments. On the other hand, phenolic compounds increased constantly, more intensively at the beginning and in the middle of fermentation and slowly at the end. The highest concentration of total phenolic $(1951.5 \pm 2.6 \mathrm{mg} / \mathrm{L})$ at the beginning of alcoholic formation had 
Table 4

Dynamics of the total phenolic compounds in the Vranec wines.

\begin{tabular}{|c|c|c|c|c|c|c|c|}
\hline Wine & $T\left({ }^{\circ} \mathrm{C}\right)$ & $\begin{array}{l}\text { Inoculation } \\
\text { amount (\%) }\end{array}$ & $\begin{array}{l}\text { Flipping } \\
\text { (num/ } \\
24 \mathrm{~h})\end{array}$ & 2nd day & 5th day & 9th day & 30th day \\
\hline Wine 1 & 24 & 3 & 4 & $1667.7 \pm 61.4^{\mathrm{c}}$ & $2343.7 \pm 3.3^{c}$ & $2290.2 \pm 4.0^{\mathrm{f}}$ & $2016.5 \pm 4.7^{j}$ \\
\hline Wine 2 & 24 & 3 & 4 & $1951.5 \pm 2.6^{\mathrm{a}}$ & $2438.5 \pm 18.5^{a}$ & $2688.7 \pm 10.2^{c}$ & $2393.7 \pm 5.4^{f}$ \\
\hline Wine 3 & 24 & 3 & 4 & $1271.3 \pm 3.5^{\mathrm{e}}$ & $2301.8 \pm 19.8^{\mathrm{d}}$ & $2455.3 \pm 5.7^{\mathrm{d}}$ & $1938.5 \pm 8.7^{\mathrm{k}}$ \\
\hline Wine 4 & 20 & 2 & 4 & $1122.0 \pm 4.2^{\mathrm{g}}$ & $1689.5 \pm 14.3^{1}$ & $1790.3 \pm 21.3^{k}$ & $1583.8 \pm 6.4^{1}$ \\
\hline Wine 5 & 28 & 4 & 4 & $1728.9 \pm 6.7^{\mathrm{b}}$ & $2138.9 \pm 9.0^{\mathrm{g}}$ & $2441.3 \pm 10.0^{\mathrm{d}}$ & $2323.0 \pm 6.6^{i}$ \\
\hline Wine 6 & 20 & 3 & 2 & $1186.8 \pm 6.4^{\mathrm{f}}$ & $1901.3 \pm 12.7^{j}$ & $2421.5 \pm 2.8^{\mathrm{e}}$ & $2393.6 \pm 8.2^{f}$ \\
\hline Wine 7 & 28 & 3 & 6 & $1321.6 \pm 1.6^{\mathrm{d}}$ & $2166.7 \pm 9.8^{f}$ & $2220.1 \pm 2.0^{\mathrm{g}}$ & $2383.4 \pm 5.7^{f}$ \\
\hline Wine 8 & 28 & 3 & 2 & $1057.2 \pm 8.5^{\mathrm{h}}$ & $2237.8 \pm 9.3^{\mathrm{e}}$ & $2971.1 \pm 3.9^{a}$ & $2838.2 \pm 9.1^{b}$ \\
\hline Wine 9 & 24 & 4 & 6 & $690.3 \pm 6.4^{\mathrm{k}}$ & $2106.2 \pm 7.1^{\mathrm{h}}$ & $2288.3 \pm 3.9^{f}$ & $2420.4 \pm 3.5^{\mathrm{e}}$ \\
\hline Wine 10 & 20 & 4 & 4 & $783.9 \pm 6.4^{\mathrm{j}}$ & $2424.7 \pm 6.5^{\mathrm{a}, \mathrm{b}}$ & $2144.1 \pm 7.4^{\mathrm{h}}$ & $2341.6 \pm 4.4^{\mathrm{h}}$ \\
\hline Wine 11 & 24 & 2 & 2 & $609.6 \pm 1.3^{\mathrm{m}}$ & $1758.8 \pm 8.0^{\mathrm{k}}$ & $1891.0 \pm 2.9^{j}$ & $2362.0 \pm 3.3^{g}$ \\
\hline Wine 12 & 28 & 2 & 4 & $821.7 \pm 3.7^{\mathrm{i}}$ & $2080.8 \pm 10.9^{\mathrm{i}}$ & $1949.0 \pm 10.8^{\mathrm{i}}$ & $2609.2 \pm 9.0^{d}$ \\
\hline Wine 13 & 20 & 3 & 6 & $625.8 \pm 6.3^{1, \mathrm{~m}}$ & $2410.5 \pm 1.3^{\mathrm{b}}$ & $2407.5 \pm 3.4^{\mathrm{e}}$ & $2945.4 \pm 8.7^{\mathrm{a}}$ \\
\hline Wine 14 & 24 & 4 & 2 & $661.4 \pm 3.0^{\mathrm{k}, 1}$ & $2131.7 \pm 3.6^{\mathrm{g}}$ & $2846.9 \pm 10.7^{\mathrm{b}}$ & $2947.7 \pm 10.7^{a}$ \\
\hline Wine 15 & 24 & 2 & 6 & $667.7 \pm 8.3^{\mathrm{k}}$ & $2425.1 \pm 18.9^{a, b}$ & $2140.6 \pm 9.1^{\mathrm{h}}$ & $2670.4 \pm 12.9^{\mathrm{c}}$ \\
\hline
\end{tabular}

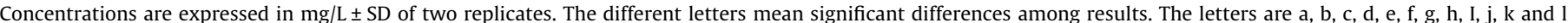
according to the decrease of the result values.

Table 5

Significant probability ( $p$-values and F-ratio) of the independent variable effects (temperature, inoculation amount, and flipping) on the total phenolic concentration.

\begin{tabular}{|c|c|c|c|c|c|}
\hline Factor & & 2nd day & 5th day & 9th day & 30th day \\
\hline \multirow[t]{2}{*}{ Temperature $\left({ }^{\circ} \mathrm{C}\right)$} & $p$-Value & 0.089 & 0.308 & 0.062 & 0.279 \\
\hline & F-ratio & 2.70 & 1.24 & 3.14 & 1.35 \\
\hline \multirow[t]{2}{*}{ Inoculation amount (\%) } & $p$-Value & $\mathbf{0 . 0 0 0}^{\mathrm{a}}$ & $\mathbf{0 . 0 0 9}^{\mathrm{a}}$ & $0.000^{a}$ & 0.389 \\
\hline & F-ratio & 11.05 & 5.82 & 22.43 & 0.98 \\
\hline \multirow[t]{3}{*}{ Flipping (times/24 h) } & $p$-Value & $\mathbf{0 . 0 0 0}^{\mathrm{a}}$ & $\mathbf{0 . 0 1 8}^{\mathrm{a}}$ & $0.012^{\mathrm{a}}$ & $\mathbf{0 . 0 0 1}{ }^{\mathrm{a}}$ \\
\hline & $F$-ratio & 13.67 & 4.84 & 5.38 & 8.88 \\
\hline & $R^{2}$ & 0.689 & 0.497 & 0.732 & 0.489 \\
\hline
\end{tabular}

a Significant at $p<0.05$.

Vranec wine 2 (Table 4). The most significant effects on the level of total phenolics on the 2th day had inoculation amount and flipping ( $p$-value are 0.000 in both cases). The Vranec wines 2, 10 and 15 showed very similar values for total phenolic content on 5 th day of alcoholic fermentation. At the end of alcoholic fermentation, the maximal concentration of total phenolics was detected in Vranec wine 8 produced at $28{ }^{\circ} \mathrm{C}$, inoculation amount of $3 \%$ and the lowest rate of flipping ( 2 times/24 h). During the peak and the end of alcoholic fermentation, the effects of inoculation amount and flipping rate were significant (Table 5). The similar concentration of total phenolics in Vranec wines 14 and 15 was detected on 30 th day where the only significant factor was rate of flipping ( $p$ value is 0.001 ). Our results were in good agreement with those published in the work of Gómez-Plaza et al. Their results indicated increased level of tannins and other phenolic compounds because of prolonged skin contact during fermentation (Gómez-Plaza, GilMuñoz, López-Roca, Martínez-Cutillas, \& Fernández-Fernández, 2001).

The active alcohol formation during the peak of the fermentation (5th day) is a precondition for strong influence of the inoculation amount to the total phenolic compounds concentration ( $p$-value is 0.009 ). In this time of the fermentation, the temperature does not influence significantly on the phenolic compounds in the wine. The flipping have rather negative influence, possibly because of a partial formation of polymeric compounds. Our findings were in good agreement with those published in the work of Leone et al. According to their findings, pump-overs had positive impact on the level of anthocyanins, catechins and total phenols for Negramano and Primitivo grapes but, little effect on anthocyanins and decreased in catechins and total phenolics for wines produced from Sangiovese variety of grapes (Leone, La Notte, \& Antonacci, 1983).

Finally, with the attenuation of the active fermentation, the inoculation amount and flipping become again the main factors which affect the total phenolic compounds extraction. This can be explained due to the fact that the trial wines have close biochemical composition; ergo the extraction of phenolic compounds is dominated by ethanol formation during fermentation.

\subsection{The impact of enological practices on the organoleptic profile of Vranec red wines with the third-stage selected yeast strains}

The tasting notes of the trial wines from the planed experiment were held and the results from spider diagrams were presented on Fig. 1.

During the preparation of the trials, spider diagrams showed a color, flavor and mostly mouthfeel characteristics. The data for variants Vranec 1, Vranec 2 and Vranec 3 were averaged, because these are basically repetitions in the center of the planned experiment and the differences are negligible.

We noticed through interpretation of the data, that the samples Vranec 9 and Vranec 13 had intense and vivid color, in aromatically pure, intense with predominant notes of ripe and dry red and black fruits and spices. The common factor in these two samples was medium temperature $\left(20-24^{\circ} \mathrm{C}\right)$, the flipping rate was high $(6$ times/24 h) since the inoculation amount varies.

The wine sample Vranec 10 was close to the mentioned wines before, but the color was less intensive with blue tints, in the aroma intensive, the notes of raspberry and sour cherry were presented and the end is slightly dry. During the production of this 
a

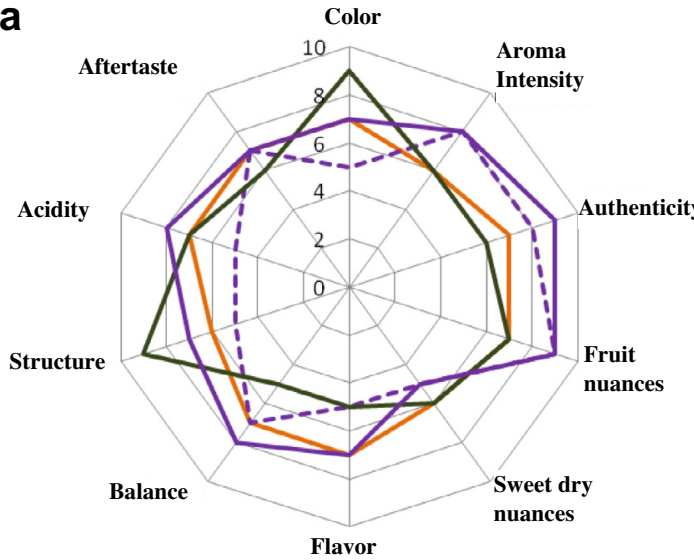

Wine; flipping; inoculation $\% ; \mathrm{T}^{\circ} \mathrm{C}$

Vranec $1 ; 4$ times; $3 \% ; 24^{\circ} \mathrm{C}$

Vranec $2 ; 4$ times; $3 \% ; 24^{\circ} \mathrm{C}$

Vranec $3 ; 4$ times; $3 \% ; 24^{\circ} \mathrm{C}$

Vranec $4 ; 4$ times; $2 \% ; 20^{\circ} \mathrm{C}$

Vranec $5 ; 4$ times; $4 \% ; 28^{\circ} \mathrm{C}$

Vranec $6 ; 2$ times; $3 \% ; 20^{\circ} \mathrm{C}$

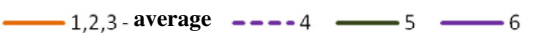

b

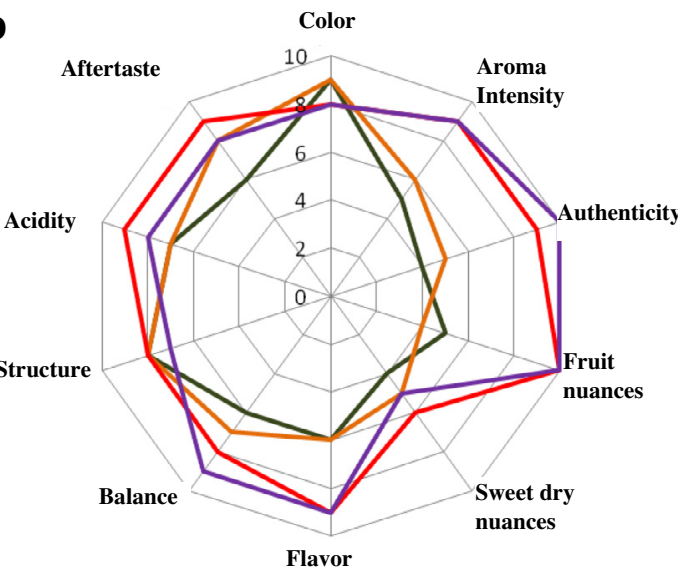

Wine; flipping; inoculation $\% ; \mathrm{T}^{\circ} \mathrm{C}$ Vranec $7 ; 6$ times; $3 \% ; 28^{\circ} \mathrm{C}$

Vranec $8 ; 2$ times; $3 \% ; 28^{\circ} \mathrm{C}$

Vranec $9 ; 6$ times; $4 \% ; 24^{\circ} \mathrm{C}$

Vranec $10 ; 4$ times; $4 \% ; 20^{\circ} \mathrm{C}$

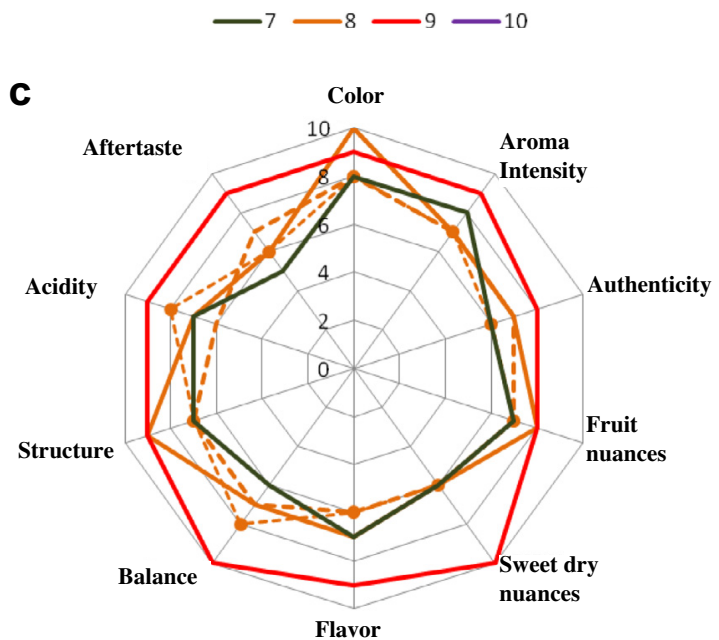

Wine; flipping; inoculation $\%$; $\mathrm{T}^{\circ} \mathrm{C}$

Vranec $11 ; 2$ times; $2 \% ; 24^{\circ} \mathrm{C}$

Vranec $12 ; 4$ times; $2 \% ; 28^{\circ} \mathrm{C}$

Vranec $13 ; 6$ times; $3 \% ; 20^{\circ} \mathrm{C}$

Vranec $14 ; 2$ times; $4 \% ; 24^{\circ} \mathrm{C}$

Vranec $15 ; 6$ times; $2 \% ; 24^{\circ} \mathrm{C}$

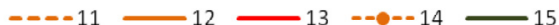

Fig. 1. (a) Spider diagram for organoleptic profile of Vranec wines 2012 (first group). (b) Spider diagram for organoleptic profile of Vranec wines 2012 (second group). (c) Spider diagram for organoleptic profile of Vranec wines 2012 (third group).

wine, the temperature was low $\left(20^{\circ} \mathrm{C}\right)$, the flipping rate was medium ( 4 times/24 h.), the inoculation amount was $4 \%$. Similar color and flavor had samples Vranec 6 and Vranec 4, which are made through almost the same factors combination. The difference is only in inoculation amount ( $3 \%$ and $2 \%$ ). This however leads to perceptible light structure, weaker flavor and dominant irritating acidity, therefore lower tasting grade. This confirmed the above established thesis, that the inoculation amount through the lighter and fast generated alcohol stimulate the extraction process and thicker the taste, enrich the flavor. For sample Vranec 6, the flipping rate was low (2 times/24 h), which lighten additionally the texture of the wine.

The samples Vranec 1, 2 and 3 were rated medium, Vranec 8 and Vranec 12 were rated lower that these above, without any 
significant difference. We could name this group "the average samples". The diagrams showed that almost all of their characteristics are rated positively, but not high and there are some in which are found insufficiency. For example, the samples Vranec 1, 2 and 3 were rated as wines with medium quality, the intensity of aroma and texture were insufficient. For wine sample Vranec 12, we observed a reduction in the flavor, but the insufficiency is some characteristics was pronounced.

Vranec 7 and Vranec 15 were characterized mostly by very intense dark ruby color, low to medium aroma intensity, phenolic, low on fruity flavor. In the mouthfeel (especially wines sample Vranec 15), the aftertaste is sharp and astringent, the flavor is weak and mainly vegetal (Lesschaeve, 2006). The samples of this group are rated as wines with lowest taste, mainly because of the lack of aroma. The two samples were kept at $28^{\circ} \mathrm{C}$, the third one at $24^{\circ} \mathrm{C}$, the flipping rate and the inoculation amount varied without tendency.

\subsection{General recommendations for improving the enological procedure for production of high quality red wines from Vranec grapes}

A strongly expressed specificity of the biological process exists and emphasized correlation between the affecting factors. Because of that, the interpretation of the results from the statistical models planned experiment and the organoleptic analysis has to be summarized with sensor characteristics of produced wines. They give to the product more complex evaluation. On this basis, we could comment the results and give recommendations about the optimization of the production process of red wines with new selected strain "F-78" from Vranec grape variety.

In the conditions of the planned experiment, the higher temperature $\left(28^{\circ} \mathrm{C}\right)$ intensified the coloration, generating dark ruby-red color, but affected to the aroma intensity, which become more phenolic. The texture is excellent, but with high astringency and dryness, in the mouth feel fermentation was detected. For the trials produced at $22^{\circ} \mathrm{C}$, the flavor was fresh fruity, intensive, the acidity was high, but juicy. Regarding the taste of the wines conducted at lower and higher temperature we can assumed that the effect of temperature dominated over the rest of the factors.

The influence of the flipping is less pronounced, mainly on the trials, where the temperature is not determinative factor on the sensory profile. The highest levels ( 6 times) and low temperature offsets the weaker extraction affect the taste of the wines. On medium level (4 times), the flipping is not recognized as tendency. The lower level of recirculation (2 times) and higher temperatures slightly decrease the intensity of aroma, while lower temperature gives a fresh and fruity flavor.

The quantity of the inoculants was medium and higher level $(3 \% ; 4 \%)$ which helps the texture of the body through more intensive fermentation and alcohol generation. The lower quantity of inoculants (2\%) leads to less flavor and higher acidity.

\section{Conclusion}

In this study, a semi-industrial lot of Vranec wine was produced. The phenolic composition and the sensory profile confirmed, that the selected local yeast strain "F-78" maintain intense, pure and complete alcoholic fermentation and the wines produced by this yeast strain enhance the typicality of the local variety (deep color, intense fruity-spicy flavor and aging potential). This strain is recommended to be applied for quality regional wines production from Tikveš region.

In the conditions of planned factorial experiment, the influence of the temperature, the amount of yeasts and the flipping of the must on the concentration of the monomer anthocyanins, total phenolic compounds, and the organoleptic profile of the trial wines from Vranec variety were studied. The results of the math models so far could be summarized by the following: the temperature has rather positive impact on the anthocyanins formation and too high temperature could lead to increased condensation and loss of anthocyanins. The inoculation material has a positive influence on the anthocyanins formation. More inoculation amount leads to faster ethanol formation and acceleration of the anthocyanins extraction. However, in the early stages with lower ethanol, the absorption of colored compounds on the yeast cells leads to relatively negative impact of the inoculation amount on the anthocyanins formation. The flipping of the must during fermentation was controversial. At one hand, more flipping leads to better contact surface and intensive extraction, but at the other hand, leads to fast condensation and production of polymeric pigments.

Based on the summarized math models and the organoleptic analysis results in the conditions of planned factorial experiment, the following modes of vinification could be recommended for production of Macedonian Vranec wines with the newly-selected local strain F-78:

- for production of the typical for the region high-extractive aged wines with intense ruby-red color, and medium-intensive aromas, dominated by fruity and spicy note, and sweet, mediumintensive fruity mouthfeel and potential in the aftertaste, we recommend a fermentation temperature of $20-24{ }^{\circ} \mathrm{C}$, intensive flipping (5-6 times/24 h), and inoculation amount 3-4\%.

- for production of commercial, young and easy to drink "Beaujoulais" wines with less ruby colors, with intensive fresh and fruity aromas, we recommend a fermentation on $20^{\circ} \mathrm{C}$, medium flipping (3-4 times, $24 \mathrm{~h}$ ) and inoculation amount 3-4\%.

Further work in this area may focus on the impact of newlyselected local strain "F-78" on the phenolic content and overall aroma of wines produced from other varieties of Macedonian grapes such as Cabernet Sauvignon, Merlot and Syrah.

\section{References}

Bakker, J., Bridle, P., Bellworthy, S. J., Garcia-Viguera, C., Reader, H. P., \& Watkins, S. J. (1998). Effect of sulphur dioxide and must extraction on colour, phenolic composition and sensory quality of red table wine. Journal of Science of Food and Agriculture, 78, 297-307.

Bakker, J., Preston, N. W., \& Timberlake, C. F. (1986). The determination of anthocyanins in aging red wines: Comparison of HPLC and spectral methods. American Journal of Enology and Viticulture, 37, 121-126.

Bambalov, G., Spasov, Ch., \& Bambalov, Kr. (2000). Isuliorung und selection von Weinhefen aus dem Westtilchen teil der Thrazischeen tiefeben. Die WeinWissensch, 55, 55-57.

Bokulich, N. A., Hwang C. F., Liu, S., Boundy-Mills, K. L., \& Mills, D. A. (2012) Profiling the yeast communities of wine fermentations using terminal restriction fragment length polymorphism analysis. American Journal of Enology and Viticulture, 63(2), 185-194.

Bokulich, N. A., Thorngate, J. H., Richardson, P. M., \& Mills, D. A. (2014). Microbial biogeography of wine grapes is conditioned by cultivar, vintage, and climate. Proceedings of the National Academy of Sciences of the United States of America, 111(1) 139-148.

Bosso, A., Guaita, M., Panero, L., Borsa, D., \& Follis, R. (2009). Influence of two winemaking techniques on polyphenolic composition and color of wines. American Journal of Enology and Viticulture, 60, 379-385.

Casassa, L. F., Bolcato, E. A., \& Sari, E. S. (2015). Chemical, chromatic, and sensory attributes of 6 red wines produced with prefermentative cold soak. Food Chemistry, 174, 110-118.

Favre, G., Peña-Neira, A., Baldi, C., Hernández, N., Traverso, S., Gil, G., \& GonzálezNeves, G. (2014). Low molecular-weight phenols in Tannat wines made by alternative winemaking procedures. Food Chemistry, 158, 504-512.

Gómez-Plaza, E, Gil-Muñoz, R, López-Roca, J. M., Martínez-Cutillas, A., \& Fernández-Fernández, J. I. (2001). Phenolic compounds and color stability of red wines: Effect of skin maceration time. American Journal of Enology and Viticulture, 52, 266-270.

Ivanova, V., Stefova, M., \& Chinnici, F. (2010). Determination of the polyphenol contents in Macedonian grapes and wines by standardized spectrophotometric methods. Journal of the Serbian Chemical Society, 75(1), 45-59. 
Ivanova-Petropulos, V., Hermosín-Gutiérrez, I., Boros, B., Stefova, M., Stafilov, T. Vojnoski, B., ... Kilár, F. (2015). Phenolic compounds and antioxidant activity of Macedonian red wines. Journal of Food Composition and Analysis, 41, 1-14.

Ivanova-Petropulos, V., Ricci, A., Nedelkovski, D., Dimovska, D., Parpinello, G. P., \& Versari, A. (2015). Targeted analysis of bioactive phenolic compounds and antioxidant activity of Macedonian red wines. Food Chemistry, 171, 412-420.

Kostadinović -Veličkovska, S., Mirhosseini, H., \& Bogeva, E. (2013). Isolation of anthocyanins by high-speed countercurrent chromatography and application of colour activity concept to different varieties of red grape pomace from Macedonia. Journal of Nutrition and Food Sciences, 3, 1-7.

Kostadinović, S., Wilkens, A., Stefova, M., Ivanova, V., Vojnoski, B., Mirhosseini, H., \& Winterhalter, P. (2012). Stilbene levels and antioxidant activity of Vranec and Merlot wines from Macedonia: Effect of variety and enological practices. Food Chemistry, 135, 3003-3009.

Leone, A. M., La Notte, E., \& Antonacci, D. (1983). Some characteristics of polyphenolic substances in red wines obtained by different processes of maceration. In C. Cantarelli \& C. Peri (Eds.), Progress in food engineering (pp. 267-277). Switzerland: Forster-Verlag.

Lesschaeve, I. (2006). The use of sensory descriptive analysis to gain a better understanding of consumer wine language. In 3rd international wine business $\mathcal{E}$ marketing research conference, Montpellier, France.

Loira, I., Vejarano, R., Morata, A., Ricardo-da-Silva, J. M., Laureano, O., González, M. C., \& Suárez-Lepe, J. A. (2013). Effect of Saccharomyces strains on the quality of red wines aged on lees. Food Chemistry, 139, 1044-1051.

Medina, K., Boido, E., Dellacassa, E., \& Carrau, F. (2012). Growth of nonSaccharomyces yeasts affects nutrient availability for Saccharomyces cerevisiae during wine fermentation. International Journal of Food Microbiology, 157, 245-250.
Monagas, M., Gómez-Cordovés, C., \& Bartolomé, B. (2007). Evaluation of different Saccharomyces cerevisiae strains for red winemaking. Influence on the anthocyanin, pyranoanthocyanin and non-anthocyanin phenolic content and colour characteristics of wines. Food Chemistry, 104, 814-823.

Pérez-Lamela, C. García-Falcón, M. S., Simal-Gándara, J.. \& Orriols-Fernández, I. (2007). Influence of grape variety, vine system and enological treatments on the colour stability of young red wines. Food Chemistry, 101, 601-606.

Puértolas, E., Saldaña, G., Álvarez, I., \& Raso, J. (2011). Experimental design approach for the evaluation of anthocyanin content of rosé wines obtained by pulsed electric fields. Influence of temperature and time of maceration. Food Chemistry, $126,1482-1487$.

Reynolds, A. Cliff, M., Girard, B., \& Kopp, T. G. (2001). Influence of fermentation temperature on composition and sensory properties of Semillon and Shiraz wines. American Journal of Enology and Viticulture, 52, 235-240.

Sacchi, K. L., Bisson, L. F., \& Adams, D. O. (2005). A review of the effect of winemaking techniques on phenolic extraction in red wines. American Journal of Enology and Viticulture, 56, 197-206.

Silva, L. R., Andrade, P. B., Valentão, P., Seabra, R. M., \& Velázquez, E. (2005). Analysis of non-coloured phenolics in red wine: Effect of Dekkera bruxellensis yeast. Food Chemistry, 89, 185-189.

Singleton, V. L., \& Rossi, A. Jr., (1965). Colorimetry of total phenolics with phosphomolybdic-phosphotungstic acid reagents. American Journal of Enology and Viticulture, 16(3), 144-158.

Vasserot, Y., Caillet, S., \& Maujean, A. (1997). Study of anthocyanin adsorption by yeast lees. Effect of some physicochemical parameters. American Journal of Enology and Viticulture, 48(4), 433-437. 